Pacific Journal of Mathematic 


\title{
AN INEQUALITY FOR OPERATORS \\ IN A HILBERT SPACE
}

\author{
BerTram MOND
}

Let $A$ be a self-adjoint operator on a Hilbert space $H$ satisfying $m I \leqq A \leqq M I, 0<m<M$. Set $q=M / m$. Let $j$ and $k$ be real numbers, $j k \neq 0, j<k$. Then

$$
\begin{aligned}
& \left(A^{k} x, x\right)^{1 / k} /\left(A^{j} x, x\right)^{1 / j} \\
& \quad \leqq\left\{j^{-1}\left(q^{j}-1\right)\right\}^{-1 / k}\left\{k^{-1}\left(q^{k}-1\right)\right\}^{1 / j}\left\{(k-j)^{-1}\left(q^{k}-q^{j}\right)(x, x)\right\}^{(1 / k)-(1 / j)}
\end{aligned}
$$

for all $x \in H(x \neq 0)$. Letting $j=-1$ and $k=1$, this inequality reduces to $(A x, x)\left(A^{-1} x, x\right) \leqq\left[(M+m)^{2} / 4 m M\right](x, x)^{2}$, the wellknown Kantorovich Inequality.

Preliminaries. We shall make use of the following four inequalities:

For $a>0, b>0$,

$$
\begin{array}{ll}
a^{\alpha} b^{1-\alpha} \leqq \alpha a+(1-\alpha) b & \text { if } 0<\alpha<1 \\
a^{\alpha} b^{1-\alpha} \geqq \alpha a+(1-\alpha) b & \text { if } \alpha<0 .
\end{array}
$$

For $j<k, 1 \leqq y \leqq q$,

$$
\begin{aligned}
\left(q^{k}-1\right) y^{j}-\left(q^{j}-1\right) y^{k}-\left(q^{k}-q^{j}\right) \geqq 0 & \text { if } j k>0 \\
-\left(q^{k}-1\right) y^{j}+\left(q^{j}-1\right) y^{k}+\left(q^{k}-q^{j}\right) \geqq 0 & \text { if } j k<0 .
\end{aligned}
$$

(1) is the well-known inequality between the arithmetic and geometric means. Simple proofs of (2), (3) and (4) can be found in a recent paper by Goldman [3].

Let $C$ be a self-adjoint operator on a Hilbert space $H$ satisfying

$$
I \leqq C \leqq q I
$$

where $I$ is the identity operator (and (5) is understood in the usual sense that $(x, x) \leqq(C x, x) \leqq q(x, x)$ for all $x \in H)$. To the real valued function $u(\lambda)$, defined and continuous on $[1, q]$, there is associated in a natural way a self-adjoint operator on $H$ denoted by $u(C)$ (see e.g. [6] pp. 265-273).

We shall make use of the following [loc. cit.]:

Lemma. If $u(\lambda) \geqq 0$ for $1 \leqq \lambda \leqq q$, then $u(C) \geqq 0$, i.e., $u(C)$ is a positive operator. 


\section{Results.}

THEOREM 1. Let $C$ be a self-adjoint operator on a Hilbert space $H$ satisfying $I \leqq C \leqq q I$. Let $j$ and $k$ be real numbers, $j<k, j k \neq 0$. The operator

$$
\left(q^{k}-1\right) C^{j}-\left(q^{j}-1\right) C^{k}-\left(q^{k}-q^{j}\right) I
$$

is positive if $j k>0$; while the operator

$$
-\left(q^{k}-1\right) C^{j}+\left(q^{j}-1\right) C^{k}+\left(q^{k}-q^{j}\right) I
$$

is positive if $j k<0$.

Proof. The theorem follows directly from (3) and (4) by virtue of the Lemma.

Letting $j=-1$ and $k=1$, Theorem 1 yields an inequality that is equivalent to one given by Diaz and Metcalf [2].

The following theorem, which is the main result of this paper, is a Hilbert space generalization of Cargo and Shisha [1] and Mond [5].

THeOREM 2. Let $A$ be self-adjoint operator on a Hilbert space $H$ satisfying $m I \leqq A \leqq M I, 0<m<M$. Set $q=M / m$. Let $j$ and $k$ be real numbers $j k \neq 0, j<k$. Then

$$
\begin{aligned}
& \left(A^{k} x, x\right)^{1 / k} /\left(A^{j} x, x\right)^{1 / j} \\
& \quad \leqq\left\{j^{-1}\left(q^{j}-1\right)\right\}^{-1 / k}\left\{k^{-1}\left(q^{k}-1\right)\right\}^{1 / j}\left\{(k-j)^{-1}\left(q^{k}-q^{j}\right)(x, x)\right\}^{(1 / k)-(1 / j)}
\end{aligned}
$$

for all $x \in H(x \neq 0)$.

Proof. Set $C \equiv A / m$. It obviously suffices to prove

$$
\begin{aligned}
& \left(C^{k} x, x\right)^{1 / k} /\left(C^{j} x, x\right)^{1 / j} \\
& \quad \leqq\left\{j^{-1}\left(q^{j}-1\right)\right\}^{-1 / k}\left\{k^{-1}\left(q^{k}-1\right)\right\}^{1 / j}\left\{(k-j)^{-1}\left(q^{k}-q^{j}\right)(x, x)\right\}^{(1 / k)-(1 / j)} .
\end{aligned}
$$

Since $C$ satisfies (5), by Theorem 1 ,

$$
\left(q^{k}-1\right)\left(C^{j} x, x\right)-\left(q^{j}-1\right)\left(C^{k} x, x\right) \geqq\left(q^{k}-q^{j}\right)(x, x) \quad \text { if } j k>0
$$

and

$$
\left(q^{k}-1\right)\left(C^{j} x, x\right)-\left(q^{j}-1\right)\left(C^{k} x, x\right) \leqq\left(q^{k}-q^{j}\right)(x, x) \quad \text { if } j k<0 .
$$

Rewrite (10) as

$$
\begin{aligned}
& \left\{-j(k-j)^{-1}\right\}\left\{j^{-1}\left(q^{j}-1\right)\left(C^{k} x, x\right)\right\}+\left\{k(k-j)^{-1}\right\}\left\{k^{-1}\left(q^{k}-1\right)\left(C^{j} x, x\right)\right\} \\
& \quad \geqq(k-j)^{-1}\left(q^{k}-q^{j}\right)(x, x)
\end{aligned}
$$

if $j k>0$, and (11) as 


$$
\begin{aligned}
& \left\{-j(k-j)^{-1}\right\}\left\{j^{-1}\left(q^{j}-1\right)\left(C^{k} x, x\right)\right\}+\left\{k(k-j)^{-1}\right\}\left\{k^{-1}\left(q^{k}-1\right)\left(C^{j} x, x\right)\right\} \\
& \quad \leqq(k-j)^{-1}\left(q^{k}-q^{j}\right)(x, x)
\end{aligned}
$$

if $j k<0$.

Assume $k>0$. Set

$a=j^{-1}\left(q^{j}-1\right)\left(C^{k} x, x\right), b=k^{-1}\left(q^{k}-1\right)\left(C^{j} x, x\right), \alpha=-j(k-j)^{-1}$.

If $j>0$, applying (2) and combining with (12), we obtain

$$
\begin{aligned}
\left\{j^{-1}\left(q^{j}-1\right)\left(C^{k} x, x\right)\right\}^{-j /(k-j)}\left\{k^{-1}\left(q^{k}-1\right)\left(C^{j} x, x\right)\right\}^{k /(k-j)} & \\
& \geqq(k-j)^{-1}\left(q^{k}-q^{j}\right)(x, x)
\end{aligned}
$$

which when raised to the power $(k-j) /(-k j)$ yields

$$
\begin{aligned}
& \left\{j^{-1}\left(q^{j}-1\right)\left(C^{k} x, x\right)\right\}^{1 / k}\left\{k^{-1}\left(q^{k}-1\right)\left(C^{j} x, x\right)\right\}^{-1 / j} \\
& \leqq\left\{(k-j)^{-1}\left(q^{k}-q^{j}\right)(x, x)\right\}^{(1 / k)-(1 / j)} \text {. }
\end{aligned}
$$

If $j<0(k>0)$, applying (1) and combining with (13) yields the reverse of (14) which, when raised to the power $(k-j) /(-k j)$, yields (15).

Finally, if $j<k<0$, set

$$
a=k^{-1}\left(q^{k}-1\right)\left(C^{j} x, x\right), b=j^{-1}\left(q^{j}-1\right)\left(C^{k} x, x\right), \alpha=k(k-j)^{-1} .
$$

Applying (2) and combining with (12) yields (14) which, when raised to the power $(k-j) /(-k j)$ yields (15). In all cases, therefore, we have (15), a rearrangement of (9). (Compare the method of proof of Theorem 2 with Goldman [3].)

The well-known [4] Kantorovich inequality, $(A x, x)\left(A^{-1} x, x\right) \leqq$ $\left[(m+M)^{2} / 4 m M\right](x, x)^{2}$, is the special case of Theorem 2 with $j=-1$, $k=1$.

\section{REFERENCES}

1. T. G. Cargo and O. Shisha, Bounds on ratios of means, J. Res. Nat. Bur. Standards 66B (1962), 169-170.

2. J. B. Diaz and F. T. Metcalf, Stronger forms of inequalities of Kantorovich and Strang for operators in a Hilbert space, Notices Amer. Math. Soc. 11, No. 1 (Jan. 1964), 92 .

3. A. J. Goldman, A generalization of Rennie's inequality, J. Res. Nat. Bur. Standards 68B (1964), 59-63.

4. L. V. Kantorovich, Functional analysis and applied mathematics, Uspekhi Math. Nauk, 3 (1948), Translated from the Russian by Curtis D. Benster, Nat. Bur. Standards, Report No. 1509., March 7, 1952.

5. B. Mond, A matrix inequality including that of Kantorovich to appear in J. Math. Analysis and Applications 13, No. 1 (Jan. 1966), 49-52.

6. F. Riesz and B. Sz-Nagy, Functional analysis, Translated from the 2nd French edition by Leo F. Boron, Frederick Ungar Pub. Co., 1955.

Received March 11, 1965. 



\section{PACIFIC JOURNAL OF MATHEMATICS}

H. SAMELSON

Stanford University Stanford, California

R. M. BLUMENTHAL

University of Washington

Seattle, Washington 98105

\section{EDITORS}

\author{
*J. DugundJI \\ University of Southern California \\ Los Angeles, California 90007 \\ RICHARD ARENS \\ University of California \\ Los Angeles, California 90024
}

\section{ASSOCIATE EDITORS}

E. F. BeCKENBACH

B. H. NEUMANN

F. WOLF

K. YosidA

\section{SUPPORTING INSTITUTIONS}

UNIVERSITY OF BRITISH COLUMBIA

CALIFORNIA INSTITUTE OF TECHNOLOGY

UNIVERSITY OF CALIFORNIA

MONTANA STATE UNIVERSITY

UNIVERSITY OF NEVADA

NEW MEXICO STATE UNIVERSITY

OREGON STATE UNIVERSITY

UNIVERSITY OF OREGON

OSAKA UNIVERSITY

UNIVERSITY OF SOUTHERN CALIFORNIA
STANFORD UNIVERSITY

UNIVERSITY OF TOKYO

UNIVERSITY OF UTAH

WASHINGTON STATE UNIVERSITY

UNIVERSITY OF WASHINGTON

AMERICAN MATHEMATICAL SOCIETY CHEVRON RESEARCH CORPORATION TRW SYSTEMS

NAVAL ORDNANCE TEST STATION 


\section{Pacific Journal of Mathematics}

Vol. 18, No. 1

March, 1966

Edward Joseph Barbeau, Semi-algebras that are lower semi-lattices ...... 1

Steven Fredrick Bauman, The Klein group as an automorphism group

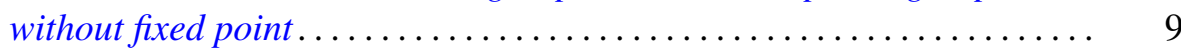

Homer Franklin Bechtell, Jr., Frattini subgroups and $\Phi$-central groups .... 15

Edward Kenneth Blum, A convergent gradient procedure in prehilbert

spaces ............................................

Edward Martin Bolger, The sum of two independent exponential-type random variables ...................................

David Wilson Bressler and A. P. Morse, Images of measurable sets .......

Dennison Robert Brown and J. G. LaTorre, A characterization of uniquely

divisible commutative semigroups........................

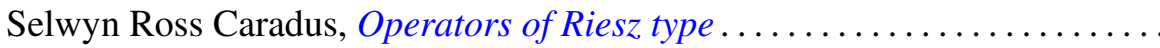

Jeffrey Davis and Isidore Isaac Hirschman, Jr., Toeplitz forms and ultraspherical polynomials ............................

Lorraine L. Foster, On the characteristic roots of the product of certain rational integral matrices of order two ......................

Alfred Gray and S. M. Shah, Asymptotic values of a holomorphic function

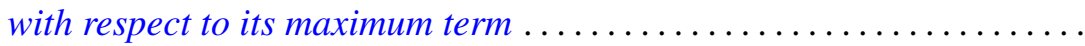

Sidney (Denny) L. Gulick, Commutativity and ideals in the biduals of

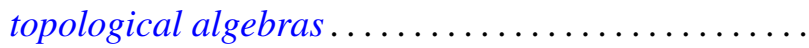

G. J. Kurowski, Further results in the theory of monodiffric functions

Lawrence S. Levy, Commutative rings whose homomorphic images are self-injective .

Calvin T. Long, On real numbers having normality of order $k$....

Bertram Mond, An inequality for operators in a Hilbert space. ...

John William Neuberger, The lack of self-adjointness in three-point boundary value problems ........................

C. A. Persinger, Subsets of $n$-books in $E^{3}$

Oscar S. Rothaus and John Griggs Thompson, A combinatorial problem in the symmetric group ............................... 175

Rodolfo DeSapio, Unknotting spheres via Smale .................. 179

James E. Shockley, On the functional equation

$$
F(m n) F((m, n))=F(m) F(n) f((m, n)) \ldots \ldots \ldots
$$

Kenneth Edward Whipple, Cauchy sequences in Moore spaces ... 